TÍTULO ORIGINAL: Training day; AÑO: 2001; DURACIÓN: 122 minutos; PAÍS: Estados

Unidos de América; DIRECTOR: Antoine Fuqua;

GUIÓN: David Ayer; MÚSICA: Mark Mancina;

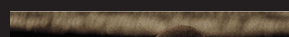

FOTOGRAFÍA: Mauro Fiore; ACTUACIONES:

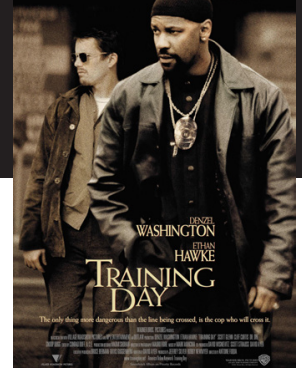

Denzel Washington, Ethan Hawke, Scott Glenn,

Tom Berenger, Harris Yulin, Raymond J. Barry,

Cliff Curtis, Snoop Dogg, Macy Gray, Charlotte

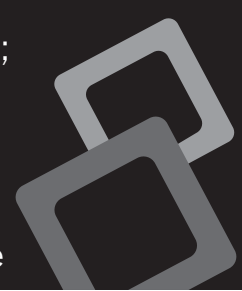

Ayanna, Eva Mendes; PRODUCCIÓN: Warner

Bros. Pictures, Village Roadshow Pictures y

NPV Entertainment; GÉNERO: Thriller, acción, película policial, drogas.

\title{
Día de Entrenamiento
}

Sin lugar a dudas, "Día de entrenamiento" constituye en un filme que sorprende gratamente en materia de producciones sobre el género policiaco y que se hayan realizado de forma destacada recientemente, teniendo en cuenta que aunque no fue un rodaje llevado a cabo en su totalidad desde un formato original y realizado con una orientación educativa, permite abordar las problemáticas y dilemas éticos en los que discurre la formación policial y la práctica policial; sin dejar de lado, el hecho de que a pesar de evidenciar algunos vacíos en la construcción narrativa, estos no representan impactos determinantes que desdibujen la rigurosidad, estilo y profesionalismo de las actuaciones tanto de los protagonistas, como del director de la película.

Se trata de una producción cinematográfica que plantea la historia de dos oficiales de policía que se encuentran en el ejercicio de su labor policial de rutina, siendo uno de estos, Jake Hoyt (Ethan Hawke), un oficial de policía novato, lleno de expectativas, con principios y valores bien marcados heredados de su proceso de formación policial adelantado en la academia de policía, donde lo principal en su profesión es brindar un buen servicio a la comunidad y enfrentar el crimen y los delitos que afectan a la sociedad; por tal motivo, Hoyt llega trasferido por voluntad propia a la unidad anti-drogas de la ciudad de los Ángeles en los Estados Unidos; siendo el escenario donde discurre su primer día de trabajo en la nueva unidad, recorriendo el sector asignado por la comandancia al lado del segundo protagonista de la película, el cual es el oficial de policía Alonzo Harris (Denzel Washington), el cual representa a un veterano oficial de policía del escuadrón anti-drogas, caracterizado por generar una ruptura entre la forma correcta de realizar los procedimientos en el ejercicio policial y la forma de lograr resultados sin medir consecuencias, siendo Harris en su papel, el oficial de policía que evoca tanto los vicios, como las formas no convencionales en que discurren las relaciones entre algunos oficiales de policía con los delincuentes en las calles; llegando a tal punto en su proceder, de no marcar una diferencia notoria entre sus actuaciones y la de los criminales que circulan en los sectores conflictivos de la ciudad de 
los Ángeles, ante los cuales se enfrenta en su labor, poniendo en escena las malas actuaciones que realiza un oficial de policía cuando la ética y la misión policial no son elementos determinantes de su accionar, demostrando el antagonismo ante lo que busca la institución policial que es el bienestar de la sociedad. A través de actuaciones no convencionales, dejar en entredicho la forma de combatir y enfrentar el crimen, cuyo objetivo principal es el de aprisionar a los capos de las drogas y combatir las estructuras delictivas responsables del tráfico en las calles de la ciudad.

En el transcurso del día de servicio, Hoyt se encuentra atónito por la forma en que su compañero Harris no respeta los mínimos éticos que debe representar un oficial de policía, demostrando en sus actos un desprecio total y permanente por los protocolos, valores y principios inculcados en la educación policial, fundamentados en la academia policial, donde sin escrúpulos irrespeta cualquier representación oficial; sin embargo, la trama de la película aumenta su intensidad y pone en escena los factibles escenarios a los que se puede ver inmerso un policía novato, entre los que se encuentran, los que son inculcados en los procesos de formación policial y que a veces contrastan con la realidad con que encuentran los policías en el ejercicio de su profesión; por tanto, es un filme que permite analizar la justificación que el oficial de policía Harris da sobre la forma poco ortodoxa de luchar contra el crimen, planteándolo con ferocidad y justificándolo como el uso de los mismos recursos con que los criminales contemporáneos se enfrentan en las calles a las fuerzas de policía, logrando con esto confundir a Hoyt en sus principios y persuadiéndole con el argumento que en la calle los policías deben estar al mismo nivel de los delincuentes si quieren lograr resultados de verdad efectivos en contra del crimen y en beneficio de la comunidad; Ilevando con esto, a analizar desde lo reflexivo sobre el papel de la educación policial impartido en la academia de policía y sobre la realidad en que discurre el ejercicio profesional de los policías en las calles combatiendo los delitos.

Seguido a esto, se puede decir que el tema central de reflexión en la educación policial a que lleva la película, se situa en la interrogante sobre cuál es la función de la "Educación Policial", evidenciando que en las calles parece que reinara lo que en palabras atribuidas a Maquiavelo sería "El fin justifica los medios", donde sin duda alguna está representado en el filme por el oficial de policía Harris, siendo el personaje que se aproxima con dicha máxima, propiciando el debate y el análisis sobre los grandes abismos que pueden llegar a presentarse entre la formación policial y la práctica policial; por tanto, se presenta en la trama de la película la posibilidad de observar el papel de Hoyt, como un oficial de policía novato 


\section{CINE}

que aún posee los valores éticos que le fueron inculcados en su proceso de formación policial, los cuales son puestos en tela de juicio y a prueba al momento de ser contrastados con la realidad encontrada en su servicio en las calles, donde se pone a dudar al ser humano en medio del juego sucio propuesto por el oficial de policía Harris, constituyéndose en un elemento que a medida que avanza el filme no plantea juicios ni morales, ni éticos; sino que permite dejar a criterio del espectador la posibilidad de considerar desde su perspectiva, la intención de instalar la responsabilidad sobre quién porta la razón en el desarrollo de la trama; comprendiendo que aunque los protagonistas están en medio y bajo responsabilidad de sus decisiones, se plantea un escenario complejo y confuso que llega a confrontar la conciencia de los espectadores que deciden analizar el desenlace de la película.

Por tal motivo, es un filme que no escatima esfuerzos en demostrar la realidad en la que pueden estar inmersos los policías en su ejercicio profesional, que sin estar caracterizado por la lógica violenta en que se presentan las escenas de acción en los filmes policiacos, el "Día de Entrenamiento", permite establecerse como una película que parece invitar a la reflexión filosófica desde la educación policial, ya que de forma directa pone en escena el dilema tanto ético, como moral de los protagonistas, dejándolos expuestos a los criterios de decisión y subjetividad que puedan elegir. Aunque ambientando algunas escenas cargadas de la violencia característica de los escenarios callejeros en que discurre la profesión policial y en los cuales convergen los delincuentes, logra un impecable trabajo sin el tinte sensacionalista del cine comercial y más bien poniendo en materia de análisis a los personajes que la protagonizan, facilitando la observación detallada en materia educativa y sumado al contraste que se presenta entre lo que se enseña en la academia policial y lo que se vive en la realidad en los escenarios donde intervienen los policías en el ejercicio de su labor.

Es de resaltar, la forma impecable en que es realizada la película, permitiendo observar en la dirección de Antoine Fuqua, un gran logro en materia de filmes policiacos, ya que articula a través de su rigurosidad y exigencia profesional el desprecio por las formas convencionales en que se realiza el cine tradicional (obviando en algunos pasajes del filme los trucos de cámaras que pretenden generar un suspenso inducido); por tal motivo, se presenta un manejo excelente de los diferentes ángulos y tomas sin exagerar la emotividad de las escenas, logrando perfectas actuaciones por parte de los protagonistas, consiguiendo depositar en ellos el manejo impecable del diálogo, la introspección y las sensacionales formas 
estéticas en que discurre el desenlace de la película. Debe exaltarse de forma objetiva el personaje protagonizado por Ethan Hawke (Hoyt), ya que a pesar de su gran talento demostrado en otras producciones, en esta logra un acabado papel, Ilevándolo sin duda alguna al máximo posible de su exigencia, sin desconocer y sin ser opacado por la excepcional actuación de la estrella de cine Denzel Whasington (Harris), quien termina desarrollando un simbólico y mítico papel en el desenlace del filme.

Relacionado con los aspectos de fondo, puede retomarse a García (2008), quien plantea que la violencia tanto directa, como estructural, hace presencia en las dinámicas sociales y sus manifestaciones, limitando la posibilidad del diálogo como mecanismo efectivo para solucionar las diferencias entre los individuos en sociedad y disminuir dicha violencia. Este autor exalta el papel que debe ejercer la educación, en este caso la policial y permitiendo analizar que

"La educación frente a esta problemática se ha venido planteando el interrogante y reto de cómo hacer para que estas tendencias puedan ser modificadas, es así como nace la Educación para la Paz. Ésta, se presentan hoy como alternativa innovadora de aprendizaje en capacidad de ajustarse a los cambios coyunturales y dar soluciones pedagógicas a los nuevos retos mundiales". (García, p. 1).

Situación que permite generar puntos de conexión con la película, cuando se pone en materia de reflexión la responsabilidad de la educación policial, la cual debe debatirse entre la lógica ética y axiológica, orientada al mantenimiento de la convivencia pacífica que deben realizar los futuros policías y alcanzado una preparación integral que les permita enfrentarse a los contextos reales que deben encarar al iniciar su labor profesional; de ahí que, se confronta la imagen de un oficial de policía corrupto (Harris), el cual sin escrúpulos hace un manejo inadecuado de su figura oficial en sociedad, con el fin de lograr sus objetivos en el bajo mundo, sin dejar de exaltar que su excelente interpretación de malvado, permite desde una postura carismática, darle el peso suficiente a un personaje que pone en tela de juicio la ética policial y la forma en que la educación policial a veces es distante de la realidad con la que se van a enfrentar los policías en las calles en su ejercicio, siendo un personaje que facilita para el espectador entre otras, la posibilidad de observar las razones que motivan sus actos y el razonamiento e inteligencia con que se desenvuelve en el bajo mundo.

Sin embargo, es una película emocionante, que permite resaltar la acertada forma de integrar a los protagonistas a una historia compleja por parte del director, realizando una selección de grandes personajes 
que le dieron tanto a los papeles protagónicos, como a los de reparto un valor agregado de realismo a una trama de género policial, donde no son los héroes tradicionales los llamados a triunfar, sino que ilustra las complejidades del ejercicio policial al enfrentarlos a un escenario palpable en las calles, donde se combate la delincuencia, realizando un engranaje con el público juvenil al vincular a personajes reconocidos como Snoop Dogg, el cual sin tener una actuación muy relevante, generan asertividad con el público juvenil contemporáneo que lo reconoce, siendo otro de los elementos para resaltar en el filme por parte del director.

En síntesis, es un filme que permite analizar el fenómeno de la violencia de forma objetiva y directa, consiguiendo llegar al interior de las relaciones que se entretejen entre los sujetos en sociedad. Provoca al sistema educativo policial a percibir desde una óptica académica y reflexiva, la forma en que presenta la violencia, quienes las experimentan y la implicación en los sujetos que están inmersos en el lugar donde convergen los hechos sociales. Identifica el escenario sobre el cual se debe situar la reflexión filosófica en la formación policial, permitiendo con ello articular desde la teoría de Bourdieu conceptos como el "Habitus", donde el sujeto construye sus relaciones de poder determinadas por la sociedad en la cual está inmerso; por ejemplo, cuando se generan acciones en detrimento de sus propios principios éticos. Con ello puede llegar a comprenderse la imposición de la violencia estructural en las relaciones de los sujetos que en ella convergen. La película "Día de Entrenamiento" evidencia la relación permanente entre el individuo y lo que converge en su contexto social de interacción, por tanto

“... ¿Cómo es posible escapar a su acción? La acción de violencia simbólica es tanto más fuerte cuanto mayor es el desconocimiento de su arbitrariedad, y uno puede destruir ese poder de imposición simbólica a partir de una toma de conciencia de lo arbitrario, lo que supone el develamiento de la verdad objetiva y el aniquilamiento de la creencia que la sustenta" (Gutiérrez, p. 298)

Finalmente, es una película que deja a disposición de los protagonistas la posibilidad de elegir y tomar decisiones; sumado a ser un filme que se reviste de una gran extrañeza, ya que llega a plantear un punto de equilibrio entre la realidad y la ficción, articulando en un mismo escenario el contraste entre las formas de educar a los individuos y la realidad del mundo donde discurren, situando a los espectadores en dicho dilema y provocando a la educación policial a replantear la forma en que se educa su potencial humano; sin embargo, a pesar de ser la típica puesta en escena 
de Hollywood, éste filme invita a romper los esquemas tradicionales del cine actual, ya que realiza una excelente actuación de los protagonistas, una impecable dirección, un contenido interesante que sin ser el más aceptado por el "statu quo" que adora el cine comercial, permite desde una gran elaboración integrarle contenido de reflexión que justifica la puesta en escena del filme; a su vez, conlleva a realizar un abordaje a los juicios morales y éticos que debe enfrentar cualquier ser humano en la existencia por tomar decisiones; no obstante presenta un final casi que anunciado en la tradición cineasta, permite ser un filme que sin estar elaborado para la educación policial, hace un llamado a la revisión de la formación policial en cuanto a la forma de educar a los policías en las academias, posicionando el contraste entre lo que significa formar para la práctica policial o formar para el procedimiento y resultados que exige la sociedad.

\section{Sinopsis elaborada por Intendente Magíster Héctor Betancur Giraldo ${ }^{1}$}

Jefe de Grupo de Investigación

Escuela de Policía Carlos Eugenio Restrepo

Policía Nacional de Colombia

\section{Referencias:}

García, A. P. S. (2009). Educación para la paz. Praxis, 5(1), 17-32.Extraído de: http://revistas.unimagdalena.edu.co/index.php/praxis/article/ view/89

Gutiérrez, A. B. (2004). Poder, habitus y representaciones: recorrido por el concepto de violencia simbólica en Pierre Bourdieu. Revista complutense de educación, Vol.15 (1), 289-300. Extraído de: http:// www. AB Gutiérrez - Revista complutense de educación, 2004 - revistas.ucm.es

1 Licenciado en Filosofía Analítica, Especialista en Educación, Cultura y Ciencia Política Universidad Nacional Abierta y a Distancia Colombia, Magíster en Educación Universidad de Medellín. Jefe de Investigación ESCER, Intendente Policía Nacional de Colombia, Estudiante de Sociología. Correo: tobybetan5@ gmail.com 